\title{
CAMPO PRÉ-EMERGENTE: BAIXA MATURIDADE DO CAMPO INSTITUCIONAL E OS DESAFIOS PARA A LEGITIMIDADE DO EMPREENDEDOR INSTITUCIONAL VAREJISTA
}

André Luiz Barbosa Da Silva ${ }^{1}$ Juracy Parente ${ }^{2}$

\footnotetext{
${ }^{1}$ Universidade Federal de Goiás

${ }^{2}$ Fundação Getulio Vargas de São Paulo
} 


\section{CAMPO PRÉ-EMERGENTE: BAIXA MATURIDADE DO CAMPO INSTITUCIONAL E OS DESAFIOS PARA A LEGITIMIDADE DO EMPREENDEDOR INSTITUCIONAL VAREJISTA}

Resumo: Esta proposta analisa a contextualização dos projetos de revitalização e o grau de maturidade institucional do polo varejista de ruas, capaz de influenciar na construção da legitimidade do empreendedor institucional varejista (EIV's). A atuação dos EIV's, convocada ou espontânea, pressupõe a desinstitucionalização da estrutura vigente, cujo propósito é construir a sua legitimidade interna e nas ruas. Objetiva-se ressaltar a oportunidade de descrever como o EI constrói a sua legitimidade em campos ainda não institucionalizados; como são tratados os polos de rua no Brasil; e como estes campos "pré-emergentes" influenciam esse processo. Esta pesquisa fundamentou-se em abordagem qualitativa e estudo de caso múltiplo envolvendo EI's no projeto de revitalização, totalizando oito polos varejistas brasileiros. Compreende-se que o grau de maturidade institucional dos polos varejistas de ruas está fundamentado nas características do campo pré-emergente e capaz de influenciar no processo.

Palavras-chave: Empreendedorismo Institucional. Legitimidade. Campo pré-emergente. Polos de ruas.

\section{Introdução}

Os polos varejistas de ruas influenciam na saúde das cidades e, por isso, precisam garantir a sua sobrevivência apresentando atratividade. A concorrência aumentou com as compras online e expansão de shopping centers, influenciando na vitalidade dos polos varejistas, gerando uma redução da competitividade, fechamento de lojas, degradação imobiliária e influência negativa nos consumidores (Chebat, Sirgy, \& St-James, 2006). No Brasil, não existem programas de revitalização com a finalidade de angariar fundos para isso. Nesse contexto, surgem empreendedores institucionais (Seo \& Creed, 2002), considerados atores motivados e habilitados a promoverem mudanças vigentes das estruturas e instituições (Greenwood \& Suddaby, 2006), (Battilana, Leca, \& Boxenbaum, 2009; Garud, Hardy, \& Maguire, 2007; Maguire, Hardy, \& Lawrence, 2004), acionando a consciência e o posicionamento do empreendedor institucional, abrindo novos conceitos e dando início ao processo de desinstitucionalização (Oliver, 1992; Scott, 2008a).

Os Empreendedores Institucionais Varejistas (EIV's) rompem as práticas internas do polo varejista, mediante ou não instituições externas ao campo, revolucionando o processo de declínio, atratividade e desenvolvimento local (Dokmeci, Altunbas, \& Yazgi, 2007; Milchen, 2005; Moreno-Jiménez, 2001), despertando consumidores (Hart, Stachow, \& Cadogan, 2013; Pryor \& Grossbart, 2007; Ward, 2007; Yeung \& Savage, 1996). A revitalização exige articulação, mobilização e estratégias de convencimento entre os seus pares varejistas, todavia é preciso provocar a desinstitucionalização e construção de legitimidade no campo de atuação. Isentos de modelo e habilidades gerenciais, além de pouca institucionalização, convém 
sistematizar para reverter o processo declinatório. Nesse contexto, os primeiros empreendedores institucionais varejistas surgem de forma espontânea, sendo convocados à construção de sua legitimidade. O empreendedorismo institucional tem crescido, embora faltem abordagens mais detalhadas a respeito da construção da legitimidade baseada na motivação e na construção de novos contextos institucionais alinhados à maturidade do campo (Buhr, 2012; Greenwood, Suddaby, \& Hinings, 2002; Stål, Bonnedahl, \& Eriksson, 2014) (Dorado, 2013), (Greenwood \& Suddaby, 2006; Maguire et al., 2004; Smith, Hoersch, \& Gordon, 1995). A maturidade dos polos varejistas influenciou na construção da legitimidade do empreendedor institucional varejista. Essa abordagem apresenta três contribuições para o empreendedorismo: quais das características dos campo institucional influenciaram na construção da legitimidade do empreendedor institucional; quais os principais resultados do projeto de revitalização, após estabelecerem um estoque mínimo de legitimidade; e, por fim, como o campo pode descontruir a legitimidade do EI.

Realizamos um estudo com empreendedores institucionais varejistas brasileiros, intencionados a participar da revitalização. Mesmo com projeto institucional predisposto e previsão de uma agenda de mudança, os EIV's encontraram forte influência advinda do campo institucional, in casu, os polos de ruas, devido a sua maturidade na construção da sua legitimidade. Fornecemos alguns insights, que podem contribuir com o aprofundamento desta abordagem, agregando valor também à teoria do empreendedorismo institucional.

\section{O processo de desinstitucionalização e a influência do grau de maturidade do campo institucional na legitimidade do Empreendedor Institucional}

A desinstitucionalização consiste na descontinuidade de uma atividade ou prática organizacional institucionalizada (Oliver, 1992; Scott, 2008). Para que isso ocorra, novas práticas não podem ser adotadas em detrimento das antigas. Uma compreensão mais completa exige maior entendimento de como as práticas institucionalizadas corroem e dão lugar às inovações (Ahmadjian \& Robinson, 2001). Compreende-se que a desinstitucionalização transforma as estruturas organizacionais possibilitando nova legitimidade e formas organizacionais, formando novo ambiente institucional (Dowling \& Pfeffer, 1975), acessando recursos para garantir a sua sobrevivência (Meyer \& Rowan, 1977; Ruef \& Scott, 1998; Singh, Tucker, \& House, 1986; Zimmerman \& Zeitz, 2002; Zucker, 1987). A construção da legitimidade pode resistir a desafios sustentando a nova instituição e adequação à ordem natural do campo, caso contrário, torna-se vulnerável, necessitando de uma base para a desinstitucionalização (Davis, Diekmann, \& Tinsley, 1994). Diante da legitimidade não aceita, as práticas vigentes são questionadas, ensejando a implantação (Ahmadjian \& Robinson, 2001) de estratégia institucional, com o propósito de ruptura e fragmentação dos significados instalados (Lawrence \& Suddaby, 2006).

Introduzir o processo de desinstitucionalização compreende uma criação de novas experiências baseadas na transformação anteriormente realizada em instituições (Battilana et al., 2009; Garud et al., 2007; Maguire et al., 2004), de forma individual ou em grupos de atores e organizações (Garud, Jain, \& Kumaraswamy, 2002; Greenwood et al., 2002; Maguire et al., 2004). Para serem empreendedores institucionais, é preciso participação ativa predisposta a mudanças, mobilização constante, liderança e articulação, em busca de recursos destinados à 
implementação de novas estruturas institucionais (Battilana et al., 2009; Boxenbaum, 2004; Greenwood \& Suddaby, 2006)

Cabe aos EIs localizarem as suas ideias dentro do conjunto de entendimentos e ações existentes, propondo o rompimento do modelo institucionalizado (Garud et al., 2002; Greenwood \& Hinings, 1996; Lawrence, Hardy, \& Phillips, 2002), provocando a desinstitucionalização. Campos em declínio, ou em crise, podem originar da convivência social, da ruptura tecnológica, da descontinuidade competitiva e das mudanças regulatórias capazes de perturbar o consenso construído socialmente, no terreno, convidando os protagonistas à introdução de novas ideias (Battilana et al., 2009; Greenwood et al., 2002; Holm, 1995), ou quando os atores dominantes começam a falhar, seja por invasão ocasionada por grupos de outros campos, fracasso organizacional no próprio campo, ou fatores exógenos (Fligstein \& Mara-Drita, 1996; Fligstein \& McAdam, 2011).

Em campos emergentes, sugere-se que o empreendedor institucional encontre um terreno comum para elaborar um discurso abrangente ajustado aos interesses e valores desses novos atores (Battilana et al., 2009; Fligstein, 1997), embora sejam de um novo campo proposto (Rao, Morrill, \& Zald, 2000). O grau de institucionalização do campo, e sua maturidade, podem influenciar diretamente na formação dos empreendedores institucionais seja no desempenho como na busca de novas estruturas institucionais (Battilana et al., 2009; Tolbert \& Zucker, 1983). Para garantir a sua atuação, o campo deve demostrar um grau mínimo de institucionalização (Fligstein, 1997; Greenwood \& Suddaby, 2006; Maguire et al., 2004), caso contrário, a sua legitimidade poderá ser questionada e agravada pela ausência de modelos claramente definidos (Déjean, Gond, \& Leca, 2004), podendo afetar o seu acesso a recursos e união das partes interessadas (Aldrich \& Fiol, 1994; Battilana et al., 2009; Maguire et al., 2004; Zelditch, 2001).

A legitimidade é sinônimo de estabilidade (Aldrich \& Fiol, 1994; Zelditch, 2001), considerado componente chave de toda a mudança (Suddaby \& Greenwood, 2005). O empreendedor e os novos atores podem mobilizar a legitimidade no campo (Rao et al., 2000), gerando tensão focada na legitimidade de um arranjo institucional vigente (Leca, Battilana, \& Boxenbaum, 2008; Seo \& Creed, 2002), o que propõe reforçar as falhas das práticas institucionalizadas, possibilitando a introdução de novo projeto institucional, a fim de unir aliados e diminuir as contradições (Boxenbaum \& Battilana, 2005; Fligstein, 1997; Holm, 1995; Seo \& Creed, 2002; Suddaby \& Greenwood, 2005). Vê-se que a maturidade do campo e o seu grau de institucionalização influenciam a legitimidade do empreendedor institucional.

Diante de campos maduros, o empreendedor institucional deve enquadrar discursos ajustados aos interesses e valores dos membros da coalização dominante (Greenwood et al., 2002; Leca et al., 2008; Suddaby \& Greenwood, 2005), cuja proposta é aumentar a ressonância de mudança, agora, em declínio. Nisso, os atores apresentam um interesse coletivo podendo encontrar soluções otimizadas, já que o campo não apresenta regras estabelecidas capazes de contribuir com a estabilização de suas interações, conquistando a cooperação (Fligstein \& Mara-Drita, 1996) e possibilidade de construção da legitimidade (Phillips, Lawrence, \& Hardy, 2004).

Em campos emergentes os EI's precisam legitimar a nova estrutura institucional, juntamente com os demais atores, que dependem deste campo (Aldrich \& Fiol, 1994; Koene, 2006). A estratégia de discurso do EI é essencial, pois carece de gerar essa nova 
institucionalização (Phillips et al., 2004), entretanto, requer seja explorada a retórica fundamentada na novidade em processo de planejamento e construção (Zimmerman \& Zeitz, 2002). Além disso, os EI's podem potencializar, de outras formas, a sua legitimidade nestes campos. Como exemplo, é possível afirmar que tal fato se dá pelo vínculo da causa à sua identidade (Wade-Benzoni et al., 2002), o que fará surgir filiações com outros atores na busca de empréstimo de legitimidade a outros atores vinculados (Battilana et al., 2009; David, Sine, \& Haveman, 2013), ou, então, sair em busca de legitimidade externa com autoridade formal intencionada a validar o seu discurso de mudança (Fligstein, 1997; Maguire et al., 2004; Phillips, Lawrence, \& Hardy, 2000).

\section{Metodologia}

Esta pesquisa apresenta estudo de caso múltiplo, de ordem qualitativa e focada em avaliar a atuação dos EIV's em projetos de revitalização de ruas. A unidade de pesquisa baseouse no próprio empreendedor institucional varejista, a fim de investigar a construção da sua legitimidade ao propor a desinstitucionalização da estrutura vigente dos polos de ruas.Foram selecionados oito polos varejistas de ruas, conforme Tabela 1, com apresentação de estágios distintos no processo de revitalização, o que significa combinar diversas atuações do empreendedor institucional varejista no processo de desinstitucionalização da estrutura vigente, cominada com a influência do campo na construção da sua legitimidade presente no projeto de revitalização.

Tabela 1. Casos de revitalização de rua

\begin{tabular}{cccc}
\hline Caso & Estado & Cidade & Nome do polo A \\
C1 & SP & São Paulo & Rua João Cachoeira \\
C2 & SP & São Paulo & Rua Oscar Freire \\
C3 & PR & Curitiba & Rua Riachuelo \\
C4 & SC & Florianópolis & Rua Vidal Ramos \\
C5 & MG & Ubá & Rua São José \\
C6 & AL & Arapiraca & Rua Anibal Lima \\
C7 & PR & Londrina & Rua Sergipe \\
C8 & PR & Maringá & Rua Santos Dumont \\
\hline
\end{tabular}

Dos oito polos varejistas pesquisados, cinco conseguiram percorrer efetivamente todo o processo de revitalização e três apresentam-se em fase de execução. Todos os empreendedores institucionais varejistas desempenharam papéis relevantes nesse projeto, aplicando diversas estratégias para a construção da sua legitimidade. Foram realizadas entrevistas, em profundidade, com foco em EIV's envolvidos diretamente no processo de revitalização e em diferentes regiões brasileiras. O estudo de caso múltiplo baseou-se em quatro fontes principais e que são entrevistas, observação, análise documental e dados secundários da web, vinculados aos projetos de revitalização de cada rua. A triangulação dos dados permitiu reduzir os riscos 
de interpretações incoerentes ou imprecisas, além de garantir maior validade entre eles (Denzin \& Lincoln, 1994; Guba \& Lincoln, 1994; Pettigrew, 1990).

A entrevista apresentou quarenta perguntas abertas, além de outras inesperadas, agregando novas abordagens à pesquisa. Foram entrevistados dezessete empreendedores institucionais varejistas, totalizando mais de 20 horas de gravações que, posteriormente, foram transcritas e codificadas, preservando o anonimato de todos, mediante a utilização de códigos individualizados conforme o caso, exemplificado na Tabela 1. Dados secundários vieram de artigos de revistas, Internet e jornais, visando o aprofundamento sobre a revitalização. Já a observação, desenvolveu-se nas dez visitas feitas em dois polos varejistas de São Paulo e com foco nos derivados da revitalização. Nesse contexto, os empreendedores varejistas disponibilizaram vários documentos sobre o projeto de revitalização. Pesquisas realizadas, com os consumidores locais, também aconteceram, entretanto, todos foram identificados e utilizados como fonte de análise. A análise dos casos percorreu duas fases, conforme proposta de Miles e Huberman (1994) e, para avançar nessa proposta, esta pesquisa utilizou o software NVivo 11, gerando maior organização das entrevistas e respectivas codificações. Na primeira fase, encontramos mais de sessenta categorias; na segunda, ocorreram várias comparações entre os discursos dos casos e vários códigos eliminados, agregados ou adicionados, respeitando a abordagem inicial de conceitos já indicados pela literatura e adicionados aos conceitos emergentes. Esta análise recursiva ampliou o aprofundamento dos dados emergindo novas reflexões sobre o processo de desinstitucionalização da estrutura vigente nos polos, assim como causou reflexão, inclusive, sobre a forma como foi realizada a construção da legitimidade do empreendedor institucional e a influência do campo na construção dessa legitimidade.

\section{Resultados}

Na seção seguinte, será apresentada a forma como a maturidade institucional dos polos varejistas de ruas influenciou na construção da legitimidade do empreendedor institucional varejista.

\section{Breve contextualização do surgimento dos EIV's}

Para dar início aos projetos de revitalização das ruas, os empreendedores institucionais varejistas foram convocados por instituições externas ao seu campo, para que pudessem atuar de maneira direta nesse contexto. Durante as entrevistas, evidenciam que, apenas nos polos C1 e $\mathrm{C} 2$, os empreendedores surgiram espontaneamente, objetivando reverter o declínio da rua. $\mathrm{O}$ primeiro, surge pela convocação de instituições legitimadas no campo tais como o Sebrae, a Associação Comercial ou Rede de Comunicação. Os varejistas foram selecionados conforme o critério estabelecido por estas instituições, posicionando-se como empreendedores institucionais (C3; C4; C5; C6; C7; C8). No segundo caso, emerge de forma espontânea (C2; C3). Essa diferença gerou impactos diretos na revitalização, nosso próximo assunto.

\section{A característica dos polos varejistas de ruas e sua influência na construção da legitimidade dos EIV's}


A partir da análise, percebeu-se que a questão da maturidade, presente no campo institucional, possibilitou que alguns elementos emergissem, sendo considerados cruciais na construção da legitimidade durante a revitalização. O surgimento destes princípios orientadores impediu o avanço da legitimidade do EIV no seu campo de atuação. Averiguou-se que os polos varejistas apresentavam determinadas práticas capazes de compor a sua estrutura, não se apresentando de maneira institucionalizada. Além dos EIV's atuarem no projeto de revitalização, empenhavam-se na formatação de um mínimo de institucionalização, inexistente anteriormente, caso contrário, não teria significado, por exemplo, mesmo diante de um projeto institucionalizado e, com base em benefícios superiores à estrutura anterior, o empreendedor conseguiria impor isso, no campo, de acordo com tais características. Vê-se que, além da necessidade de um grau mínimo de institucionalização, os atores varejistas precisam assumir uma postura gerencial buscando resultados positivos e garantindo a perenidade das estratégias implantadas.

Os elementos direcionadores e influenciadores do campo institucional, presente na construção da legitimidade do EIV's, permitiram a descoberta das características do campo pré-emergente, fundamentado nos seguintes fatores: baixo engajamento, falta de orientação de mercado, ausência de senso de rede, além das questões culturais. A conjugação destes elementos deriva da manutenção da estrutura vigente, ensejando desvios de propósitos advindos dos empreendedores institucionais, mediante a sua legitimidade. Tais características deste campo estão ligadas e se reforçam mediante a combinação, impedindo a construção da legitimidade do EIV's.

Viu-se que falta de engajamento dos varejistas dos polos (C1; C2; C3; C4; C5; C7; C8) impende a evolução do projeto de revitalização baseado em motivos comportamentais e culturais $(\mathrm{C} 1$; C2; C3; C7), o que acaba por favorecer os varejistas dos polos, alertando para a não visualização dos benefícios gerados pela revitalização. Tem-se como exemplo a melhoria na atratividade e nas vendas. Nesses casos, apresentam como justificativas a falta de tempo, baixo interesse nas reuniões e problemas financeiros para contribuir com projeto. Os varejistas dos polos não apresentaram um grau de presença física e emocional suficientes em relação às atividades do projeto de revitalização, portanto, baixa interação. Isso influenciou diretamente na construção da legitimidade, já que, para reverter este cenário, o EIV's tiveram que desenvolver diversas estratégias de convencimento.

\footnotetext{
"Mas no inicio, para começar a fazer um processo de revitalização desse, aparecia as vezes duas, três pessoas em uma reunião. Que era para aparecer trinta pessoas, aparecia três pessoas. Quer dizer, é de chorar. Tu te prepara para fazer um trabalho bom, se dedica, e aparece três, quatro, cinco. Dependendo da reunião, tinha quóruns assim, bastante inexpressivos, bastante baixa a presença. Mas existia uma vontade muito grande de fazer, e que a gente via que valia a pena investir. " (C4)

Eu te dou um doce se você conseguir envolver empresários, porque eles não querem. É essa a fala. Não, o que você está falando é bonito, mas não consegue, porque a gente não conseguiu. Então foi um trabalho de quase dois anos de, realmente, ir lá, conversa com empresário, vai, conversa com outro, começa a mostrar o que que é possivel (C7)
}

Observou-se uma falta de conectividade entre a prática de gestão e a visão futura de negócio $(\mathrm{C} 1 ; \mathrm{C} 4 ; \mathrm{C} 5 ; \mathrm{C} 6 ; \mathrm{C} 7 ; \mathrm{C} 8)$. Geralmente, espera-se que varejistas procurem soluções para 
os seus problemas de negócio relacionado aos consumidores e suas necessidades. Essa falta de orientação influencia no desempenho do polo de rua, como de fato ocorreu com o surgimento de shopping centers $(\mathrm{C} 1 ; \mathrm{C} 4 ; \mathrm{C} 5 ; \mathrm{C} 6 ; \mathrm{C} 7 ; \mathrm{C} 8)$ e novos canais de compra $(\mathrm{C} 1 ; \mathrm{C} 5 ; \mathrm{C} 7)$. Nesse contexto, notou-se que os varejistas não apresentaram resposta efetiva e coordenada para acompanhar as tendências mercadológicas focadas nas ruas, entrando em declínio, cabendo ao EIV's a reversão deste processo.

"[...] com a ascensão do e-commerce, o shopping chegou, então foi toda uma situação, se o comércio local parar, estagnar, vai morrer, ninguém vai sair de casa para comprar, vai comprar pela internet ou vai no shopping comprar, se precisar de algo de pronta entrega. Se eles não fizerem algo diferente o comércio vai morrer." (C6)

“[...] mas por parte dos empresários eu vejo isso mesmo, falta essa visão, alguém que tenha uma visão um pouquinho mais visionária de futuro, falar: 'pô, esse projeto é uma boa, Sebrae, Fecomércio, a prefeitura, estão investindo, estão botando dinheiro para nos ajudar', isso é coisa que nem precisava acontecer, porque o setor privado, por si só, tinha que caminhar. Eles poderiam se organizar e fazer o negócio funcionar e melhorar a rua, só que eles não fazem". (C8)

Para caminhar com foco na orientação de mercado, é preciso acionar o senso de coletividade ou de rede. Processos de orientação de mercado, praticados nos polos, precisam de esforços coletivos e coordenados, para que seja possível permitir a criação de uma estrutura robusta e que resulte em percepções positivas ao consumidor, variáveis não encontradas pelos EIV's neste formato de campo pré-emergente $(\mathrm{C} 1 ; \mathrm{C} 2 ; \mathrm{C} 3 ; \mathrm{C} 4 ; \mathrm{C} 5 ; \mathrm{C} 6 ; \mathrm{C} 7 ; \mathrm{C} 8)$. A falta de coletividade ou cooperatividade implica acionar princípios que apenas reduzem a legitimidade do EIV's, não permitindo a conectividade de relações entre os varejistas, EIV's e demais instituições externas ao campo. Além disso, um dos fatores que reforçaram ainda mais as características do campo pré-emergentes são os aspectos culturais $(\mathrm{C} 1 ; \mathrm{C} 3 ; \mathrm{C} 6 ; \mathrm{C} 7 ; \mathrm{C} 8)$, como por exemplo, idade dos varejistas dos polos.

\footnotetext{
"É como eu te disse, é o perfil mais egoísta, ele via o vizinho como um concorrente, por mais que estejam ali há anos, ele via como concorrente, então cada um queria ser maior que o outro, eles não tinham a percepção de que eles juntos, eles iam ganhar mais." (C6)
}

A apresentação dessas características nos permitiu gerar as categorias sobre as características deste campo pré-emergente, que interferiu diretamente na construção da legitimidade do EIV's. O polo varejista exigiu empenho destes empreendedores para desinstitucionalizar práticas vigentes desordenadas, porém com institucionalização em fase embrionária, reforçada pela ausência de orientação de mercado, engajamento, senso de rede e questões culturais. O esforço dos EIV's almejava avançar na agenda de mudança proposta pelo projeto de revitalização, cujo propósito era obter resultados coletivos baseados na reversão do declínio dos polos varejistas. 


\section{Principais resultados alcançados pelos EIV's no projeto de revitalização, após a construção da sua legitimidade do polo varejista}

Mesmo com as características do campo pré-emergente influenciando na legitimidade dos EIV's, resultados concretos no projeto de revitalização foram atingidos. Nos casos C6 e $\mathrm{C} 8$, os EIV's encontraram um grau de dificuldade elevado ao estabelecer uma relação com as autoridades políticas locais voltadas a endossar o projeto. A falta de transparência e compromisso público descontruíram e fragilizaram a legitimidade destes EIV's com os seus pares varejistas, gerando desconfiança e falta de credibilidade, prejudicando o projeto. A participação do setor público é considerada ponto central do processo de revitalização, em razão da legitimidade elevada no campo. Quando o setor público endossa o projeto, os EIV's elevam a sua legitimidade no polo varejista, facilitando a articulação $(\mathrm{C} 1 ; \mathrm{C} 2 ; \mathrm{C} 3 ; \mathrm{C} 4 ; \mathrm{C} 7)$, o que resulta em resultados mais efetivos.

Os EIV's, que avançaram na etapa da revitalização, apresentaram resultados comuns, revertidos em segurança, adequação da infraestrutura, atração de novos varejistas, maior visibilidade na mídia, referência para outros polos varejistas, retorno dos consumidores, valorização imobiliária e aumento das vendas $(\mathrm{C} 1 ; \mathrm{C} 3 ; \mathrm{C} 4 ; \mathrm{C} 5)$. No caso $\mathrm{C} 1$, por exemplo, varejistas perceberam um aumento de $20 \%$ a $30 \%$ nas vendas. Cabe ressaltar a relevância da perenidade das instituições criadas, com o intuito de representar as ruas. EIV's atuam em projetos para garantir a sua continuidade no desenvolvimento estratégias mercadológicas para a rua. Os EIV's ainda encontram resistência dos atores varejistas devido o baixo engajamento e orientação de mercado, sendo, portanto, considerado de rede $(\mathrm{C} 1 ; \mathrm{C} 3 ; \mathrm{C} 5 ; \mathrm{C} 7)$. Mesmo apresentando resultados concretos, os varejistas do polo não assumem uma posição colaborativa. Esse contexto gerou uma segunda preocupação, que elucida como EIV's são convocados para a gestão e uma instituição considerada estratégica.

Apenas em C2, o EIV desenvolveu de fato um modelo de negócio para a Associação Comercial da Rua de maneira sustentável, e que são as formas de captação de varejistas, materiais institucionais, equipe própria, estratégias mercadológicas, desenvolvimento de eventos, comunicação constante e atividade remunerada. Em C1, os EIV's até desenvolveram uma associação inicial, entretanto, foi desativada devido a força do campo e desvio de interesses dos EIV's. Os melhores resultados foram apresentados pelos empreendedores institucionais de origem espontânea $(\mathrm{C} 1 ; \mathrm{C} 2)$ ao assumirem as características de empreendedores institucionais, participando ativamente em suas inquietações, cuja movimentação propiciou reverter a estrutura vigente dos seus polos.

\section{Influência do polo varejista na desconstrução da legitimidade do EIV's}

Após os resultados positivos sobre o processo da revitalização, alguns EIV's tentaram manter-se no polo varejista visando defender os interesses coletivos desses atores $(\mathrm{C} 1 ; \mathrm{C} 2$; C3; C5; C7; C8). No entanto, a imaturidade e a institucionalização dos polos de ruas geraram desconstrução da sua legitimidade. Os EIV's atuantes na rua possuem as suas respectivas lojas e agem em prol da revitalização como voluntários convocados, muito embora não recebam remuneração para conduzir tais projetos ou para realizarem a gestão de Instituições. Isso eleva a demanda de atividades e conflitos de interesses entre o atuar como EIV e posicionar-se como 
varejista. Como os varejistas dos polos não respondem e não promovem diálogo coeso, no intuito de melhorar a atratividade local, EIV's desistem da proposta e seguem rumo aos novos projetos e oportunidades pessoais:

Ela consegue trazer alguns empresários. Mas talvez também fosse o momento de renovação de liderança. Só que ao mesmo tempo, não tem alguém que tenha essa mesma pegada que ela, entendeu?" (C4)

Além disso, o próprio polo varejista pode gerar um isolamento do EIV referente a agenda de mudança institucional e este perde a sua legitimidade no campo institucional, não conseguindo mais ter acesso às organizações externas ao polo, já que a sua legitimidade foi descontruída. Observamos que as características do campo pré-emergente dificultam a construção da legitimidade do EIV e fragmenta a nova proposta institucional rubricada pelos EIV's, o que contribui para a desconstrução da legitimidade dos EIV's, que são forçados a retornar a sua posição inicial no campo institucional. Nesse caso, nenhum varejista é beneficiado e a sua estrutura é enfraquecida, fortalecendo a desinstitucionalização do polo de rua no campo.

\section{Discussão dos resultados}

Os resultados indicam uma forte influência do grau de institucionalização na construção da legitimidade do empreendedor institucional varejista. Os EIV's e os polos varejistas concentravam-se no campo organizacional, os polos varejistas de ruas, denominado pré-emergente. Nota-se que esse campo estava enraizado no baixo engajamento e orientação de mercado, falta de senso de coletividade e atores agindo de forma situacional, alinhados aos benefícios de seus interesses. Essas características são consideradas menos propensas à construção da legitimidade do EIV's, além de reforçar o baixo grau de institucionalização dos polos varejistas de rua.

Os EIV's sofreram forte influência sobre a baixa institucionalização dos polos varejistas de rua. Para isso, usaram diversas estratégias para construir a sua legitimidade, buscando elevar o grau de institucionalização da rua. Ou seja, mesmo com objetivo claro e direcionado a criar novas formas institucionais (Battilana et al., 2009; Garud et al., 2007), além de promover mudanças (Suddaby \& Greenwood, 2005), os empreendedores varejistas não conseguiram romper as barreiras impostas pelo campo pré-emergente. Vê-se, nesse contexto, que o compartilhamento dos esquemas do campo gerou comportamentos padronizados (Scott, 2008) pelos atores varejistas alocados nos oitos polos de ruas e que, com isso, acabaram por assumir uma posição dominante. Os empreendedores institucionais varejistas acreditavam que, mediante declínio do polo, a descontinuidade destas práticas do campo pré-emergente poderia ser rompida pela revitalização. Tentaram desinstitucionalizar essas práticas, a fim de propiciar a abertura para adoção de uma nova legitimidade institucional (Aldrich \& Fiol, 1994; Dacin, Goodstein, \& Scott, 2002). Nesse ínterim, o projeto de revitalização apresentava uma proposta coerente, focada na atratividade local (Dokmeci et al., 2007; Milchen, 2005; Moreno-Jiménez, 2001) e atração de novos consumidores (Hart et al., 2013; Pryor \& Grossbart, 2005; Ward, 2007). Assim, o polo varejista apresentava-se de forma desorganizada e fragilizada, e o projeto 
de revitalização reforçava as falhas existentes, cujos seus resultados seriam superiores à estrutura vigente, corroborando com a ideia de unir os atores e reduzir as contradições no campo (Boxenbaum \& Battilana, 2005; Fligstein, 1997; Holm, 1995; Seo \& Creed, 2002; Suddaby \& Greenwood, 2005).

O campo pré-emergente não apresentou um grau mínimo de institucionalização necessária para garantir a atuação integral do empreendedor institucional, reforçando o posicionamento dos Fligstein (1997); Greenwood \& Suddaby (2006); Maguire et al. (2004). Diante do exposto, averiguou-se que o empreendedor precisa garantir o grau mínimo de institucionalização e de legitimidade, caso contrário, será questionado de forma constante (Déjean et al., 2004). Essa configuração dificultou o acesso dos empreendedores a recursos e na capacidade de unificar diversos atores varejistas (Aldrich \& Fiol, 1994; Battilana et al., 2009; Zelditch, 2001). Mediante a baixa institucionalização, dois pontos relevantes são encontrados no campo de pesquisa, a começar pela forma como surgiram os empreendedores institucionais e, o segundo, evidencia a forma como cada perfil atuou nesta configuração do campo préemergente. Com relação ao campo, mesmo sendo apresentadas as suas resistências, os empreendedores institucionais conseguiram avançar até determinado ponto e de certa forma, o que viabilizou a construção de um grau menor de legitimidade ao atuarem no projeto de revitalização. Nos casos de empreendedores espontânos $(\mathrm{C} 1 ; \mathrm{C} 2)$, assumiram comportamentos de empreendedores institucionais (Battilana et al., 2009; Boxenbaum, 2004; Greenwood \& Suddaby, 2006), emergindo uma inquietação perante o declínio (C1), ou interesse em elevar a atratividade do polo (C2).

Nesse entremeio, construíram o projeto de revitalização de forma independente, financiando os custos entre os seus pares e, posteriormente, buscando fontes de financiamento com empresas privadas. Também criaram associações para elevar a sua legitimidade no campo, além de conseguirem acesso e apoio do setor público. Os empreendedores convocados surgem pelas instituições externas ao polo e com elevado grau de legitimidade no campo institucional tais como o Sebrae, as Associações Comerciais e a Rede de televisão. A inquietação do declínio dos polos emerge destas instituições e não dos varejistas, além disso, a escolha deles é realizada pelas instituições, que buscam relação com polo, sendo o empreendedor convocado a assumir a condição de facilitador no projeto de revitalização.

Ao analisar os resultados finais do projeto de revitalização, viu-se que os casos em que empreendedores institucionais surgiram, de forma espontânea, obtiveram mais sucesso quando comparados aos espontâneos. Isso vem reforçar que empreendedores institucionais precisam realmente apresentar alguns elementos, dentre eles, o estoque mínimo de legitimidade, foco comum e consequente representatividade baseada na interação entre seus pares. Os EIV's tentaram elevar a sua legitimidade utilizando o setor público e criando ligação permissiva (Nisco et al. 2008 apud Grunig \& Hunt,1984), que, com externalização das suas características de regulação, autoridade e legislação foi possível elevar o grau de legitimidade dos EIV'S, influenciando no campo pré-emergente. Com aprovação e apoio do setor público, os EIV's conseguiram avançar na construção da sua legitimidade para atuar na revitalização. O setor público permitiu, aos varejistas dos polos, compreenderem as intenções do projeto de revitalização e início da sua pré-institucionalização, ampliando o engajamento deles no projeto, o que possibilitou maior visibilidade nos meios de comunicação, resultado utilizado pelos EIV's como estratégia de mobilização e convencimento perante os demais varejistas. 
Quadro 1. Tipologia dos campos institucionais

\begin{tabular}{|c|c|c|c|c|}
\hline & Pré-emergente & Emergente & Maduro & Declínio \\
\hline Características & $\begin{array}{c}\text { As práticas são } \\
\text { fundamentadas no } \\
\text { baixo engajamento, } \\
\text { falta de senso de rede } \\
\text { e orientação } \\
\text { mercadológicas. } \\
\text { Fortalecendo a } \\
\text { inexistência da } \\
\text { institucionalização. } \\
\text { Tais características } \\
\text { são reforçadas pelas } \\
\text { questões culturais } \\
\text { praticadas pelo } \\
\text { campo, como a busca } \\
\text { da defesa de } \\
\text { interesses individuais } \\
\text { e imediatista. } \\
\text { Iniciativas de } \\
\text { institucionalização } \\
\text { sofrem riscos de } \\
\text { descontinuidade } \\
\text { imediata. }\end{array}$ & $\begin{array}{c}\text { Apresenta algum } \\
\text { grau de interesse } \\
\text { mútuo. } \\
\text { Existe relativamente } \\
\text { pouca ação } \\
\text { coordenada entre } \\
\text { eles }\end{array}$ & $\begin{array}{c}\text { As interações e } \\
\text { rotinas já são } \\
\text { estabelecidas entre } \\
\text { os participantes que } \\
\text { possuem forte } \\
\text { consciência de suas } \\
\text { posições no campo. } \\
\text { As relações de } \\
\text { poder e as coalizões } \\
\text { são definidas com } \\
\text { objetivo comum }\end{array}$ & $\begin{array}{l}\text { Gerados pela } \\
\text { convivência social, a } \\
\text { ruptura tecnológica, } \\
\text { a descontinuidade } \\
\text { competitiva e as } \\
\text { mudanças } \\
\text { regulatórias que } \\
\text { podem perturbar o } \\
\text { consenso construído } \\
\text { socialmente no } \\
\text { terreno. } \\
\text { Os atores } \\
\text { dominantes em uma } \\
\text { arena começam a } \\
\text { falhar, seja por } \\
\text { invasão por grupos } \\
\text { de outros campos, } \\
\text { fracasso } \\
\text { organizacional } \\
\text { dentro do campo ou } \\
\text { fatores exógenos }\end{array}$ \\
\hline
\end{tabular}

No entanto, isso não significa que a legitimidade dos EIV's romperam a estrutura do campo pré-emergente por meio desta ligação permissiva. Se por um lado o poder público assumiu um papel central no processo de revitalização, por outro, provocou a ineficiência no trabalho de gestão pública, potencializando a resistência dos varejistas e reduzindo a legitimidade dos EIV's. Em todos os casos analisados, as Prefeituras apresentaram problemas nas etapas do projeto de revitalização. A escassez de recursos financeiros, conflito de interesses entre varejistas e o partido vigente na Prefeitura ensejou um clima de desconfiança na manutenção da parceria com a rua, baixa mobilização pública e desenvolvimento de estratégias de convencimento em relação à relevância do projeto com atrasos no cronograma das obras e manutenção da rua que, mesmo após revitalização, contribuiu negativamente na construção da legitimidade dos EIV's.

Logo após a criação das mínimas condições de atuação, os EIV's observaram o descompasso entre as suas ações e as respostas dos seus pares varejistas. Neste interim, os lojistas apresentavam baixo engajamento, baixo senso de coletividade e, como consequência, potencializaram a vulnerabilidade do polo, devido à falta de orientação mercadológica. Esse conjunto de fatores enfraqueceu o processo de construção da legitimidade do EIV's e, em alguns casos, a estrutura mínima construída, por eles, visa romper o campo pré-emergente. Em alguns polos, ou existiu a desativação das instituição da rua, devido a ausência de contribuição 
e interesse, ou os varejistas estavam direcionados a agirem de maneira situacional em benefícios de seus interesses individuais, aproveitando-se das ações do EIV's para se beneficiarem, mas sem o propósito de engajar nos projetos propostos pelos EIV's, de forma coletiva, impactando na construção da legitimidade. Ou seja, mesmo propondo uma agenda de mudança, estratégias de convencimento e mobilização (Boxenbaum \& Battilana, 2005; Holm, 1995; Seo \& Creed, 2002) construíram alternativas melhores (Leca et al., 2008; Seo \& Creed, 2002), com capacidade de alinhar soluções e interesses coletivos (Snow \& Benford, 1992 apud Rao, Morrill, \& Zald, 2000), com isso, os EIV's não conseguiram romper a estrutura do campo préemergente a ponto de criarem condições mínimas de legitimidade e elevar o grau de institucionalização dos polos varejistas.

Mesmo recorrendo ao endosso de instituições externas, visando construir a sua legitimidade, também não foram reconhecidas e validadas, mas estavam em concordância com os varejistas de rua. Isso reforça o posicionamento e maturidade, presente no campo institucional, capaz de influenciar diretamente na legitimidade do EI (Fligstein, 1997; Greenwood \& Suddaby, 2006; Maguire et al., 2004), ressaltando que devem existir condições mínimas para garantir a sua atuação. Conclui-se que esta pesquisa contribuiu e ampliou a discussão ao apresentar quais fatores que podem gerar essa inferência direta na construção da legitimidade do EI, pouco explorada pela literatura até então, além de demonstrar como o campo pode contribuir para a perda da legitimidade.

\section{Conclusĩes}

Nesta pesquisa, discutiu-se sobre como a maturidade do campo institucional do polo de rua pode influenciar na construção da legitimidade do empreendedor institucional varejista e quais são os principais resultados alcançados no projeto de revitalização. Viu-se que os problemas enfrentados por esses EIV's são semelhantes no decorrer da construção de sua legitimidade e que tem por base a desinstitucionalização da estrutura vigente e o baixo grau de institucionalização dos polos varejistas. Mesmo o polo apresentando problemas de declínio e, consequentemente, abrindo a oportunidade para a desinstitucionalização destas práticas, os EIV's encontraram diversas barreiras ao executarem o projeto de revitalização. Em pesquisas, detectou-se que o EIV possuía um projeto de revitalização que buscava iniciar um processo de institucionalização dos polos varejistas, tentando, com isso, mobilizar o campo, a fim de buscar essa nova institucionalização. Questiona-se, diante disso, por que encontraram dificuldades em legitimar a sua atuação diante da implantação de um projeto voltado a atingir benefícios coletivos? Nossa pesquisa demostra que tais fatores, apresentados pela literatura, foram insuficientes para responder este questionamento. No entanto, nossa pesquisa ressalta que a falta de engajamento, orientação de mercado, senso de rede e influências culturais foram os ingredientes que faltaram para gerar o mínimo de institucionalização, capazes de gerar tais benefícios coletivos.

Os EI's promovem novas formas organizacionais, em novos campos, e que dependem muito mais da retórica. De início, esses empreendedores não tinham uma coordenação, planejamento ou uma agenda em comum visando transformar o polo varejista, antes de serem convocados para assumirem este papel. 
A construção da legitimidade, em campos pré-emergentes, refere-se às quatro dimensões: (a) habilidades e condições do EI, no intuito de identificar o grau de institucionalização do campo, (b) maturidade dos atores, (c) estratégias para construção da legitimidade e (d) riscos de desvios. Os resultados não confirmaram a expectativa de que empreendedores institucionais conseguem atuar e legitimar os seus projetos de desinstitucionalização efetuando mudanças, assumindo uma posição dominante e mobilizando atores próximos (Battilana et al., 2009; Fligstein, 1997; Greenwood et al., 2002; Holm, 1995; Rao et al., 2000). Os empreendedores espontâneos foram superiores, mas não necessariamente o convocado, pois, mesmo com empréstimo de legitimidade de outras instituições externas ao seu campo, não conseguirão avançar com a sua agenda de mudança.

Além disso, não havia esquemas compartilhados no campo alimentando atores varejistas enraizados no baixo engajamento e com baixa orientação de mercado e aspectos culturais, e não há consciência de rede de colaboração, impedindo o avanço do processo desinstitucionalização da estrutura vigente, influenciando negativamente a construção da legitimidade do EIV's. Aqui, reforçamos e contribuímos, nesta vertente, como a atuação do EI deve considerar e conciliar o grau institucional do campo, maturidade dos atores, definindo as estratégias de legitimidade. Reforçamos que, além de apresentar comportamentos de EI e possuir um projeto relevante em benefício dos atores, devemos analisar antecipadamente a maturidade do campo e perfil dos atores para, posteriormente, delinear estratégias de construção de legitimidade. Compreender a visão destes autores ajudaria na complementação e validação desta pesquisa sobre o seu posicionamento no campo, gerando uma série de novas razões que ajudariam a explicar a falta de apoio na construção da legitimidade e quais estratégias estariam mais coerentes para elevar o grau institucional nos polos varejistas.

\section{Referências}

Ahmadjian, C. L., \& Robinson, P. (2001). Safety in numbers: Downsizing and the deinstitutionalization of permanent employment in Japan. Administrative Science Quarterly, 46(4), 622-654. http://doi.org/10.2307/3094826

Aldrich, H. E., \& Fiol, C. M. (1994). Fools Rush in? The Institutional Context of Indsutry Creation. The Academy of Management Review, 19(4), 645-670. http://doi.org/10.2307/258740

Battilana, J., Leca, B., \& Boxenbaum, E. (2009). How Actors Change Institutions: Towards a Theory of Institutional Entrepreneurship. The Academy of Management Annals, 3(1), 65107. http://doi.org/10.1080/19416520903053598

Boxenbaum, E. (2004). For symposium: Perspectives on Institutional Entrepreneurship Academy of Management Annual Conference New Orleans , August 6-11 , 2004 The Innovative Capacity of Institutional Entrepreneurs : A Reconstruction of Corporate Social Responsibility The Innova. Business.

Boxenbaum, E., \& Battilana, J. (2005). Importation as innovation: transposing managerial practices across fields. Strategic Organization, 3(4), 355-383. http://doi.org/10.1177/1476127005058996

Buhr, K. (2012). The Inclusion of Aviation in the EU Emissions Trading Scheme: Temporal Conditions for Institutional Entrepreneurship. Organization Studies, 33(11), 1565-1587. 
http://doi.org/10.1177/0170840612463324

Chebat, J. C., Sirgy, M. J., \& St-James, V. (2006). Upscale image transfer from malls to stores: A self-image congruence explanation. Journal of Business Research, 59(12), 1288-1296. http://doi.org/10.1016/j.jbusres.2006.09.007

Dacin, M. T., Goodstein, J., \& Scott, W. R. (2002). Institutional Theory and Institutional Change: Introduction to the Special Research Forum. Academy of Management Journal, 45(1), 43-56.

David, R. J. R., Sine, W. D. W., \& Haveman, H. A. H. (2013). Seizing opportunity in emerging fields: How institutional entrepreneurs legitimated the professional form of management consulting. Organization Science, 24(2), 356-377. http://doi.org/10.1287/orsc.1120.0745

Davis, G., Diekmann, K., \& Tinsley, C. (1994). The Decline and Fall of the Conglomerate Firm in the 1980s: the Deinstitutionalization of an Organizational Form. American Sociological Review, 59(4), 547-570. http://doi.org/10.1017/CBO9781107415324.004

Déjean, F., Gond, J.-P., \& Leca, B. (2004). Measuring the Unmeasured: An Institutional Entrepreneur Strategy in an Emerging Industry. Human Relations, 57(6), 741-764. http://doi.org/10.1177/0018726704044954

Denzin, N., \& Lincoln, Y. S. (1994). Handbook of qualitative research. In SAGE (Ed.), (Thousand O, pp. 1-17).

Dokmeci, V., Altunbas, U., \& Yazgi, B. (2007). Revitalisation of the Main Street of a Distinguished Old Neighbourhood in Istanbul. European Planning Studies, 15(1), 153166. http://doi.org/10.1080/09654310601016788

Dorado, S. (2013). Small Groups as Context for Institutional Entrepreneurship: An Exploration of the Emergence of Commercial Microfinance in Bolivia. Organization Studies, 34(4), 533-557. http://doi.org/10.1177/0170840612470255

Dowling, J., \& Pfeffer, J. (1975). Organizational Legitimacy:Social Values and Organizational Behavior. The Pacific Sociological Review, 18(1), 122-136.

Fligstein, N. (1997). Social skill and the theory of fields. American Behavioral Scientist, 40, 397-405. http://doi.org/0803973233

Fligstein, N., \& Mara-Drita, I. (1996). How to make a market: Reflections on the attempt to create a single market in the European Union. American Journal of Sociology, 102(1), 133. http://doi.org/10.1086/230907

Fligstein, N., \& McAdam, D. (2011). Toward a General Theory of Strategic Action Fields. Sociological Theory, 29(1), 1-26. http://doi.org/10.1111/j.1467-9558.2010.01385.x

Garud, R., Hardy, C., \& Maguire, S. (2007). Institutional Entrepreneurship as Embedded Agency: An Introduction to the Special Issue. Organization Studies, 28(7), 957-969. http://doi.org/10.1177/0170840607078958

Garud, R., Jain, S., \& Kumaraswamy, A. (2002). Institutional Entrepreneurship in the Sponsorship of Common Technological Standards : The Case of Sun Microsystems and Java. The Academy of Management Journal, 45(1), 196-214.

Greenwood, R., \& Hinings, C. R. (1996). Understanding radical organizational change: Bringing together the old and the new institutionalism. Academy of Management Review, 21(4), 1022-1054.

Greenwood, R., \& Suddaby, R. (2006). Institutional entrepreneurship in mature fields: The big five accounting firms. Academy of Management Journal, 49(1), 27-48. 
http://doi.org/10.5465/AMJ.2006.20785498

Greenwood, R., Suddaby, R., \& Hinings, C. R. (2002). Theorizing Change: The Role of Professional Associations in the Transformation of Institutionalized Fields. Academy of Management Journal, 45(1), 58-80. http://doi.org/10.2307/3069285

Guba, E. G., \& Lincoln, Y. S. (1994). Competing Paradigms in Qualitative Research. Handbook of Qualitative Research, 105-117. http://doi.org/http://www.uncg.edu/hdf/facultystaff/Tudge/Guba\%20\&\%20Lincoln\%201 994.pdf

Hart, C., Stachow, G., \& Cadogan, J. W. (2013). Conceptualising town centre image and the customer experience. Journal of Marketing Management, 29(15-16), 1753-1781. http://doi.org/10.1080/0267257X.2013.800900

Holm, P. (1995). The Dynamics of Institualization: Transformation Processes in Norwegian Fisheries. Administrative Science Quarterly, 40(3), 398-422.

Koene, B. a. S. (2006). Situated human agency, institutional entrepreneurship and institutional change. Journal of Organizational Change Management, 19(3), 365-382. http://doi.org/10.1108/09534810610668364

Kupke, \& Valerie. (2004). Identifying the dimensions to retail centre image. Journal of Property Investment \& Finance, 22(4), 298-306. http://doi.org/10.1108/14635780410550858

Lawrence, T., Hardy, C., \& Phillips, N. (2002). Institutional Effects of Interorganizational Collaborations: The Emergency of Proto-Institutions. Academy of Management Journal, 45(1), 281-290. http://doi.org/10.2307/3069297

Lawrence, T., \& Suddaby, R. (2006). Institutions and institutional work. (S. R. Clegg, C. Hardy, T. B. Lawrence, \& N. W.R., Eds.). London: Sage.

Leca, B., Battilana, J., \& Boxenbaum, E. (2008). Agency and Institutions: A Review of Institutional Entrepreneurship (No. 08-096). HBS Working Paper.

Maguire, S., Hardy, C., \& Lawrence, T. B. (2004). Institutional Entrepreneurship in emerging fields : HIV / AIDS treatment advocacy in Canada. The Academy of Management Journal, 47(5), 657-679.

Meyer, J., \& Rowan, B. (1977). Institutionalized Organizations: Formal Structure as Myth and Ceremony. American Journal of Sociology, 83(2), 340-363.

Milchen, J. (2005). The benefits of doing business locally. American Institute of Business Alliances, Boseman, MT., 1-2.

Moreno-Jiménez, A. (2001). Interurban shopping, new town planning and local development in Madrid metropolitan area. Journal of Retailing and Consumer Services, 8, 291-298.

Oliver, C. (1992). The Antecedents of Deinstitutionalization. Organization Studies, 13(4), $563-$ 588. http://doi.org/10.1177/017084069201300403

Pettigrew, A. M. (1990). Longitudinal Field Research on Change: Theory and Practice. Organization Science, 1(3), 267-292. http://doi.org/doi: 10.2307/2635006

Phillips, N., Lawrence, T. B., \& Hardy, C. (2000). Inter-organizational collaboration and the dynamics of institutional fields. Journal of Management Studies, 37(1), 23-41. http://doi.org/10.1111/1467-6486.00171

Phillips, N., Lawrence, T. B., \& Hardy, C. (2004). Discourse and institutions. Academy of Management Review, 29(4), 636-652. http://doi.org/10.5465/AMR.2004.14497617 
Pryor, S., \& Grossbart, S. (2005). Ethnography of an American Main Street. International Journal of Retail \& Distribution Management, 33(11), 806-823. http://doi.org/10.1108/09590550510629400

Pryor, S., \& Grossbart, S. (2007). Creating meaning on main street: Towards a model of place branding. Place Branding and Public Diplomacy, 3(4), 291-304. http://doi.org/10.1057/palgrave.pb.6000080

Rao, H., Morrill, C., \& Zald, M. N. (2000). Power plays: How social movements and collective action create new organizational forms. Research in Organizational Behavior, 22, 237 281. http://doi.org/10.1016/S0191-3085(00)22007-8

Ruef, M., \& Scott, W. R. (1998). A Multidimensional Model of Organizational Legitimacy: Hospital Survival in Changing Institutional Environments. Administrative Science Quarterly, 43(4), 877-904. http://doi.org/10.2307/2393619

Scott, W. R. (2008). Institutions and Organizations: Ideas, Interests, and Identities. Sage Publications (Vol. 3). http://doi.org/10.1016/S0263-2373(97)89895-7

Seo, M.-G., \& Creed, W. E. D. (2002). Institutional Contradictions , and Institutional Change : a Dialectical. Management, 27(2), 222-247.

Singh, J. V, Tucker, D. J., \& House, R. J. (1986). Organizational Legit- imacy and the Liability of Newness Robert J . House. Administrative Science Quarterly, 31(2), 171-193.

Smith, D. L., Hoersch, A. L., \& Gordon, P. R. (1995). Problem-Based Learning in the Undergraduate Geology Classroom, 43, 149-152.

Stål, H. I., Bonnedahl, K. J., \& Eriksson, J. (2014). The challenge of introducing low-carbon industrial practices: Institutional entrepreneurship in the agri-food sector. European Management Journal, 32(2), 203-215. http://doi.org/10.1016/j.emj.2013.06.005

Suddaby, R., \& Greenwood, R. (2005). Rhetorical Strategies of Legitimacy. Administrative Science Quarterly, 50(1), 35-67. http://doi.org/10.2189/asqu.2005.50.1.35

Tolbert, P., \& Zucker, L. (1983). Institutional Sources of Change in the Formal Structure of Organizations: The Diffusion of Civil Service Reform. Administrative Science Quarterly, 28(1), 22-39.

Wade-Benzoni, K. A., Hoffman, A. J., Thompson, L. L., Moore, D. A., Gillespie, J. J., \& Bazerman, M. H. (2002). Resolution in ideologically based negotiations: The role of values and institutions. Academy of Management Review, 27(1), 41-58.

Ward, K. (2007). Creating a personality for downtown: Business Improvement Districts in Milwaukee. Urban Geography, 28(8), 781-808.

Yeung, H., \& Savage, V. (1996). Urban imagery and the Main Street of the nation: The legibility of Orchard Road in the eyes of Singaporeans. Urban Studies, 33(3), 473-495.

Zelditch, M. (2001). Processes of legitimation: Recent developments and new directions. Social Psychology Quarterly, 64(1), 4-17. http://doi.org/10.2307/3090147

Zimmerman, M. a., \& Zeitz, G. J. (2002). Beyond survival: Achieving new venture growth by building legitimacy. Academy of Management Review, 27(3), 414-431. http://doi.org/10.5465/AMR.2002.7389921

Zucker, L. (1987). Institutional theories of organization. Annual Review of Sociology, 13, 443 464. 